Supporting Information

\title{
Compact, "Clickable" Quantum Dots Photoligated with Multifunctional Zwitterionic Polymers for Immunofluorescence and In Vivo Imaging
}

Wentao Wang, ${ }^{1}$ Erna A. van Niekerk, ${ }^{2}$ Yang Zhang, ${ }^{3}$ Liang Du, ${ }^{1}$ Xin Ji, ${ }^{1}$ Sisi, Wang, ${ }^{1}$ James D. Baker, ${ }^{3}$ Kimberly Groeniger, ${ }^{2}$ Françisco M. Raymo ${ }^{3}$ and Hedi Mattoussi ${ }^{1 *}$

1. Department of Chemistry and Biochemistry, Florida State University, 95 Chieftan Way, Tallahassee, Florida 32306, USA

2. Department of Neurosciences, University of California, San Diego, La Jolla, California, 92093, USA

3. Laboratory for Molecular Photonics, Department of Chemistry, University of Miami, 1301 Memorial Drive, Coral Gables, Florida 33146, USA

Email: mattoussi@fsu.edu

Materials. Poly(isobutylene-alt-maleic anhydride) (PIMA) (average MW: 6000 Da, 12 - 200 mesh, 85\%), lipoic acid ( $\geq 98.0 \%$ ), tetraethylene glycol (TEG) (average MW: $190 \mathrm{Da}, 99 \%$ ), ethylenediamine (99.5\%), N,N-dimethylamino propylamine (99\%), 1,3-propanesultone (98\%), ditert-butyl dicarbonate (99\%), ethylenediamine ( $\geq 99 \%)$, triethylamine ( $\geq 99 \%)$, hydrochloric acid (37\%), dicyclohexylcarbodiimide (99\%), triphenylphosphine $\quad(99 \%), \quad 4-(N, N-$ dimethylamino)pyridine $(\geq 99 \%), 1,1^{\prime}$-carbonyldiimidazole $(\geq 97 \%)$, sodium azide $(\geq 99.5 \%)$, methanesulfonyl chloride $(\geq 99.7 \%)$ along with most of the chemicals used were purchased from Sigma Aldrich (St Louis, MO). Solvents were purchased from Sigma Aldrich (St Louis, MO). Deuterated solvents used for NMR experiments were purchased from Cambridge Isotope Laboratories (Andover, MA). DBCO-Sulfo-NHS ester (MW = 532.5 Da, >95\%) was purchased from Click Chemistry Tools (Scottsdale, AZ). TrkB (80G2) rabbit monoclonal antibody (MW = $140 \mathrm{kDa}$ ) was purchased from Cell Signaling Technology (Danvers, MA). Recombinant BDNF $(\mathrm{MW}=27 \mathrm{kDa}$ ) was purchased from PeproTech, Inc. (Rocky Hill, New Jersey). The chemicals and solvents were used as received, unless otherwise specified.

The syntheses were carried out under $\mathrm{N}_{2}$ passed through an $\mathrm{O}_{2}$ scrubbing tower, unless

otherwise stated. Air sensitive materials were handled in an Mbraun Labmaster glovebox, and standard Schlenk techniques were used when handling air-sensitive materials. 
Instrumentation. The photoligation experiments were carried out using a UV photoreactor Model LZC-4V (Luzchem Research Inc., Ottawa, Canada). The reactor is equipped with14 lamps, 6 of those lamps are installed on top and 4 on each side, and provide a irradiation band with peak at $350 \mathrm{~nm}$ and intensity of $4.5 \mathrm{~mW} / \mathrm{cm}^{2}$. The optical absorption data were collected using a UV-vis absorption spectrophotometer (UV 2450 model, Shimadzu, Columbia, MD). The fluorescence spectra were collected using a Fluorolog-3 spectrofluorometer (HORIBA Jobin Yvon, Edison, NJ) equipped with PMT and CCD detectors. The NMR data were recorded using a $600 \mathrm{MHz}$ spectrometer (Bruker SpectroSpin, Billerica, MA), while the FT-IR spectra were collected using a Spectrum 100 FT-IR Spectrometer (PerkinElmer, Waltham, MA). The zeta potential data were acquired using a Zetasizer Nano ZS (Malvern Panalytical, United Kingdom). Immunofluorescence images were collected on Zeiss LSM 880 confocal microscope with 20X objective (Zeiss, Germany). Z-stack images were taken across $13-15 \mu \mathrm{m}$ of tissue at optimal intervals, with 1024 x 1024 resolution, averaging 4 lines per section, sequentially scanning at $405 \mathrm{~nm}$ with detector range at $611-689 \mathrm{~nm}$ for QDs. Live cell images were captured with a 20X objective, Leica SP8 lightning confocal microscope (Leica Microsystems) with excitation at $405 \mathrm{~nm}$ set to $2 \%$ power and emission spectrum set to $600-700 \mathrm{~nm}$. Phase contrast images were taken simultaneously. Average 4 lines were taken per image, at 1024 x 1024 resolution. In-vivo fluorescence images of embryo were acquired using a Leica SP5 confocal laser-scanning microscope (Leica, Buffalo Grove, IL). The fluorescence of GFP were detected with an excitation wavelength of $488 \mathrm{~nm}$ and emission wavelength of $500-550 \mathrm{~nm}$. The fluorescence of QDs were detected with an excitation wavelength of $561 \mathrm{~nm}$ and emission wavelength of $575-650 \mathrm{~nm}$.

Growth of CdSe-ZnS core-shell QDs. The QDs were synthesized in two reaction steps via reduction of organometallic precursors at high temperature in a hot coordinating solvent mixture. The CdSe core was grown first via reduction of cadmium and selenium precursors at temperature of $\sim 300-350{ }^{\circ} \mathrm{C}$ using a coordinating solvent mixture made of trioctyl phosphine (TOP), trioctyl phosphine oxide (TOPO) and alkylamines along with a small fraction hexylphosphonic acid; the CdSe nanocrystal size was controlled via small adjustments in the precursor concentrations and annealing temperature. ${ }^{1,2}$ Overcoating the CdSe core with a shell made of a few monolayers $(\sim 5$ - 6) of $\mathrm{ZnS}$ using zinc and sulfur precursors, but reaction was carried out at lower temperature $\left(150-180{ }^{\circ} \mathrm{C}\right) .{ }^{3-5}$ All QDs were prepared to have similar overcoating ZnS layer; the overall coreshell size difference is primarily due to variation in the core radius. Further details are available in our previous report. ${ }^{6}$

Syntheses of lipoic acid-amine (LA-NH2), zwitterion-amine ( $\left.\mathrm{ZW}-\mathrm{NH}_{2}\right)$ and azide-TEG-NH2. The amine-terminated lipoic acid precursor $\left(\mathrm{LA}-\mathrm{NH}_{2}\right)$ was synthesized by coupling lipoic acid to ethylenediamine. ${ }^{7}$ The synthesis of $\mathrm{ZW}-\mathrm{NH}_{2}$ was carried out following literature protocols. ${ }^{6,8}$ The precursors $\mathrm{N}_{3}$-TEG- $\mathrm{NH}_{2}$ was synthesized in our laboratory starting from tetraethylene glycol (average MW 190 Da), following the procedures detailed in previous work. ${ }^{9}$ 
BCA protein assay. The average number of $\alpha$-TrkB antibody per QD (in the conjugates) was extracted using Pierce BCA Protein Assay. The principles, experimental procedures and protocols for preparing the bovine serum albumin (BSA) standards and bicinchoninic acid Working Reagents (BCA WR) are available at the website (Thermo Fisher Scientific, link: https://www.thermofisher.com/order/catalog/product/23225\#/23225).

Two sets of sample mixtures were prepared for the assay. One contains the BSA standards mixed with the BCA WR and the other contains the QD-Ab conjugates mixed with the BCA WR. Each was prepared by mixing $200 \mu \mathrm{L}$ of the sample (BSA standards or QD-Ab conjugates) with $200 \mu \mathrm{L}$ of BCA WR. The final concentration of BSA standards used in this study ranged from 100 to $0 \mu \mathrm{g} / \mathrm{mL}$, as shown in Table S1. The final concentration of the QD-conjugates was estimated by comparing the absorbance of the conjugate dispersion at $350 \mathrm{~nm}$ to the extinction coefficient of the QDs $\left(\varepsilon_{350}\right)$. All mixtures were incubated at $37{ }^{\circ} \mathrm{C}$ for 1 hour at the same time. The formed BCA- $\mathrm{Cu}^{+1}$ complex in the QD-Ab mixture was separated from the QD-conjugates using a centrifugal membrane filtration device, as shown in Figure S4C. The absorbance at $562 \mathrm{~nm}$ for all the samples was measured using a 96-well plate. A standard curve was generated by plotting the blank (i.e., $0 \mu \mathrm{g} / \mathrm{mL}$ )-corrected absorbance at $562 \mathrm{~nm}$ for each BSA standard vs. concentration in $\mu \mathrm{g} / \mathrm{mL}$. The antibody concentration in the conjugate samples was determined by comparing the absorbance at $562 \mathrm{~nm}$ of the bicinchoninic acid (BCA)- $\mathrm{Cu}^{+1}$ complex, separated from the conjugates, to the standard curve. The raw data are provided in Table $\mathbf{S 1}$ and the standard curve is shown in Figure S4D.

Table S1. Raw data and average absorbance values for each content deduced from the BCA assay.

\begin{tabular}{|c|c|c|c|c|c|}
\hline Content & $\begin{array}{c}\text { Protein Concentration } \\
(\mu \mathrm{g} / \mathrm{mL})\end{array}$ & Well & $\begin{array}{c}\text { Raw data @ } \\
562 \mathrm{~nm}\end{array}$ & $\begin{array}{c}\text { Average Abs @ } \\
562 \mathrm{~nm}\end{array}$ & $\begin{array}{c}\text { Blank-corrected Abs } \\
\text { @ } 562 \mathrm{~nm}\end{array}$ \\
\hline Standard 1 & 0 & $\begin{array}{l}\mathrm{B} 08 \\
\mathrm{~A} 08\end{array}$ & $\begin{array}{l}0.094 \\
0.114\end{array}$ & 0.104 & 0 \\
\hline Standard 2 & 1.5625 & $\begin{array}{l}\mathrm{B} 07 \\
\mathrm{~A} 07\end{array}$ & $\begin{array}{l}0.123 \\
0.126 \\
\end{array}$ & 0.1245 & 0.0205 \\
\hline Standard 3 & 3.125 & $\begin{array}{l}\text { B06 } \\
\text { A06 }\end{array}$ & $\begin{array}{l}0.164 \\
0.167\end{array}$ & 0.1655 & 0.0615 \\
\hline Standard 4 & 6.25 & $\begin{array}{l}\text { B05 } \\
\text { A05 }\end{array}$ & $\begin{array}{l}0.239 \\
0.246\end{array}$ & 0.2425 & 0.1385 \\
\hline Standard 5 & 12.5 & $\begin{array}{l}\mathrm{B} 04 \\
\mathrm{~A} 04\end{array}$ & $\begin{array}{l}0.404 \\
0.408 \\
\end{array}$ & 0.406 & 0.302 \\
\hline Standard 6 & 25 & $\begin{array}{l}\mathrm{B} 03 \\
\mathrm{~A} 03\end{array}$ & $\begin{array}{l}0.736 \\
0.729\end{array}$ & 0.7325 & 0.6285 \\
\hline Standard 7 & 50 & $\begin{array}{l}\mathrm{B} 02 \\
\mathrm{~A} 02\end{array}$ & $\begin{array}{l}1.276 \\
1.274\end{array}$ & 1.275 & 1.171 \\
\hline Standard 8 & 100 & $\begin{array}{l}\mathrm{B} 01 \\
\mathrm{~A} 01\end{array}$ & $\begin{array}{l}2.314 \\
2.275 \\
\end{array}$ & 2.2945 & 2.1905 \\
\hline QD-Ab & to be determined & $\begin{array}{l}\mathrm{CO2} \\
\mathrm{CO1}\end{array}$ & $\begin{array}{l}1.308 \\
1.312\end{array}$ & 1.31 & 1.206 \\
\hline
\end{tabular}



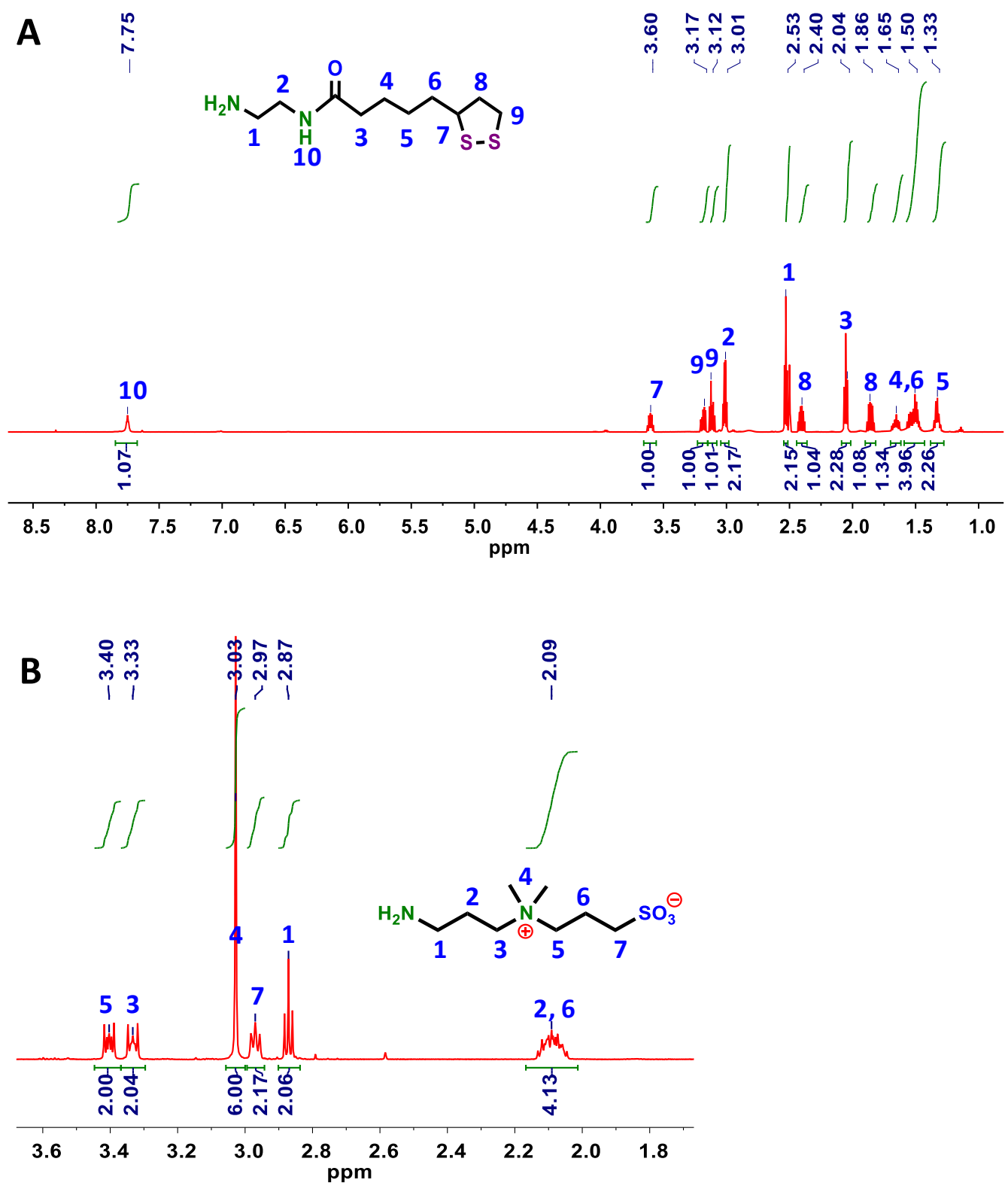

Figure S1. ${ }^{1} \mathrm{H}$ NMR spectra lipoic acid-amine $\left(\mathrm{LA}-\mathrm{NH}_{2}\right)$ in DMSO- $d_{6}(\mathrm{~A})$, and zwitterion-amine $\left(\mathrm{ZW}-\mathrm{NH}_{2}\right)$ in $\mathrm{D}_{2} \mathrm{O}(\mathrm{B})$. The spectra are reproduced from our previous report. ${ }^{10}$ 


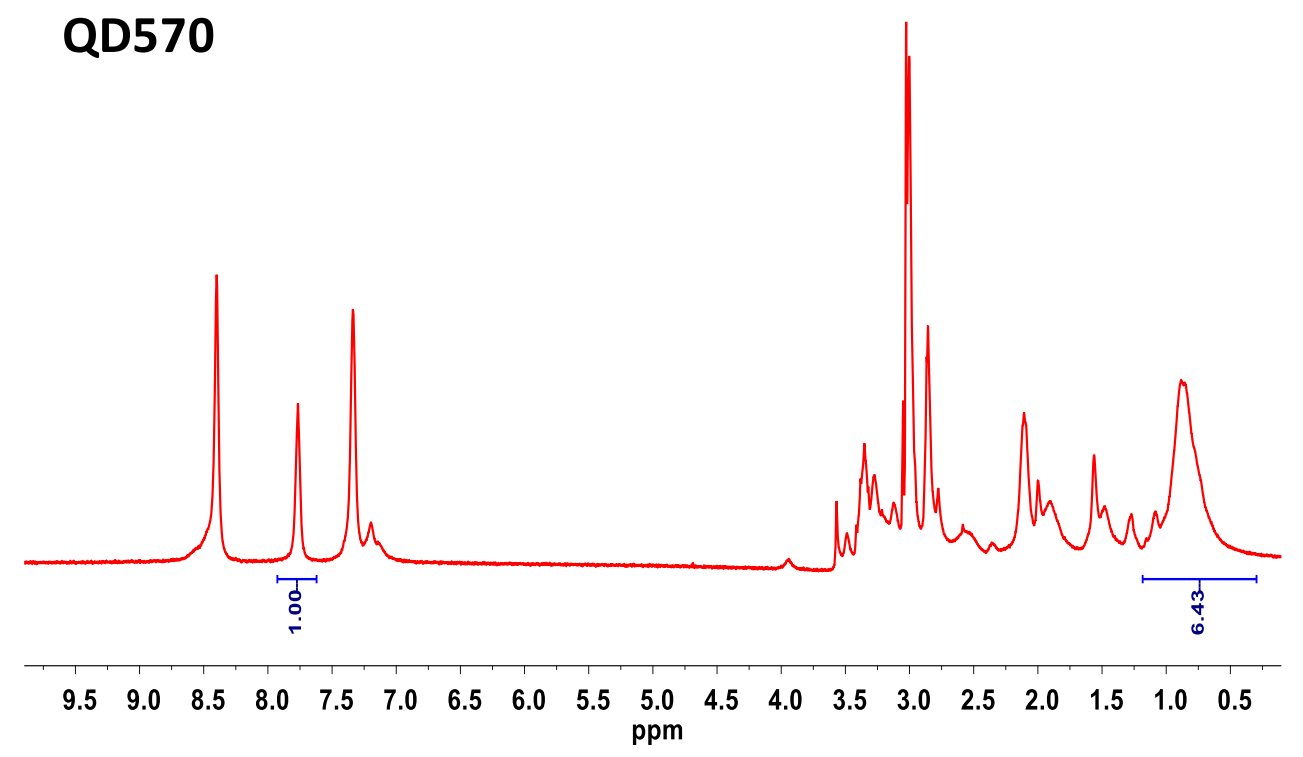

\section{QD633}

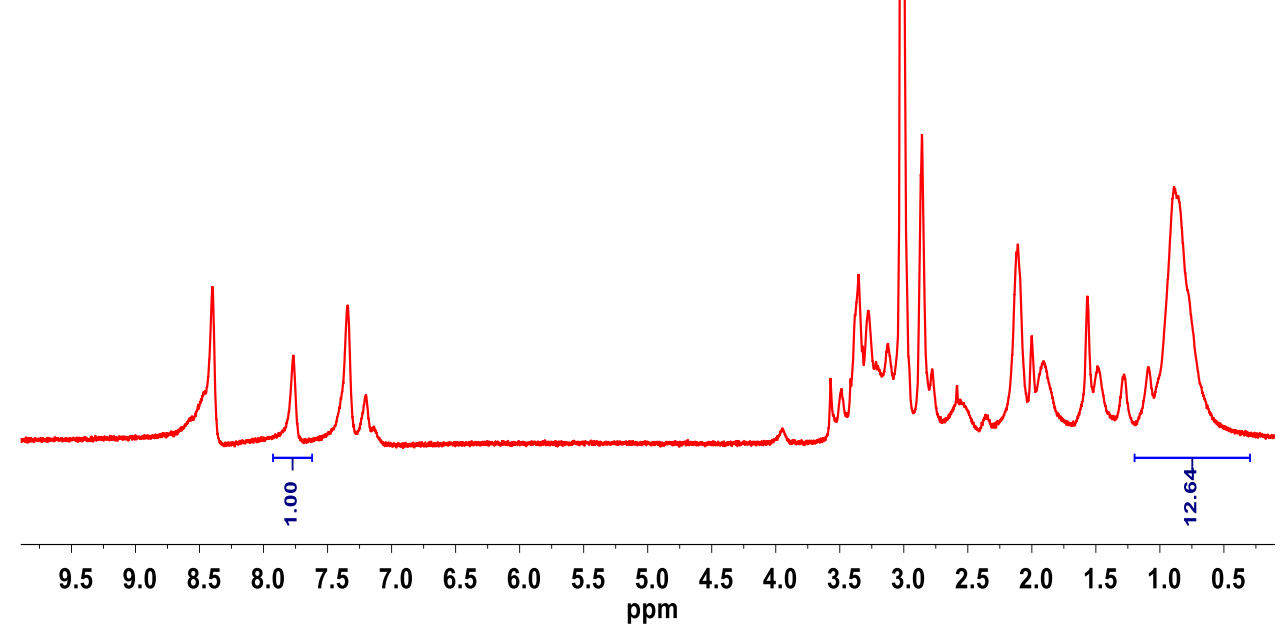

Figure S2. Ligand counting: pulsed-field gradient-based water suppression ${ }^{1} \mathrm{H}$ NMR spectra of QD570 and QD633 caped with LA/His-PIMA-ZW, mixed with pyridine as a standard. 

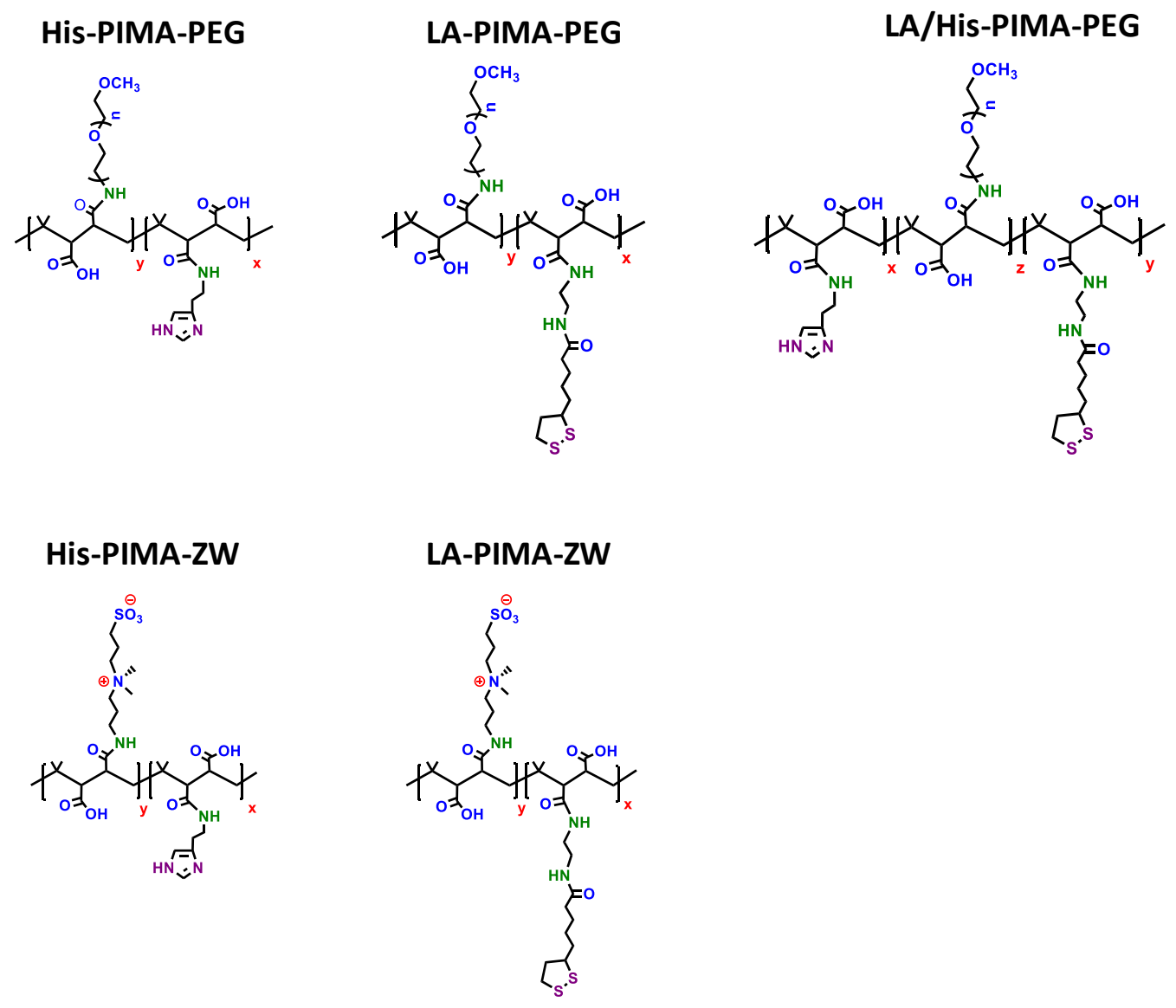

Figure S3. Chemical structures of the polymer ligands listed in Table 2. 


\section{A}

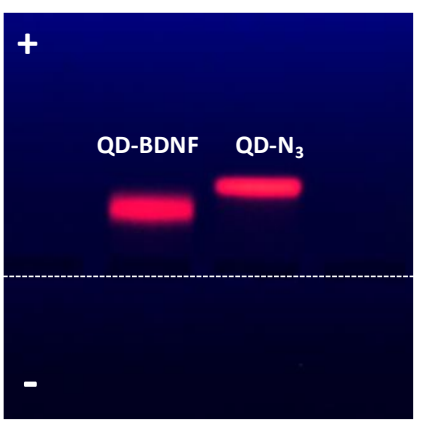

B
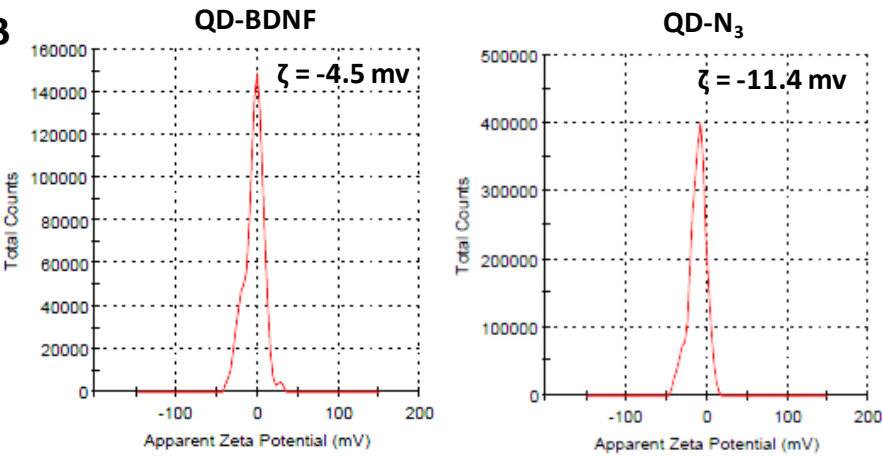

C

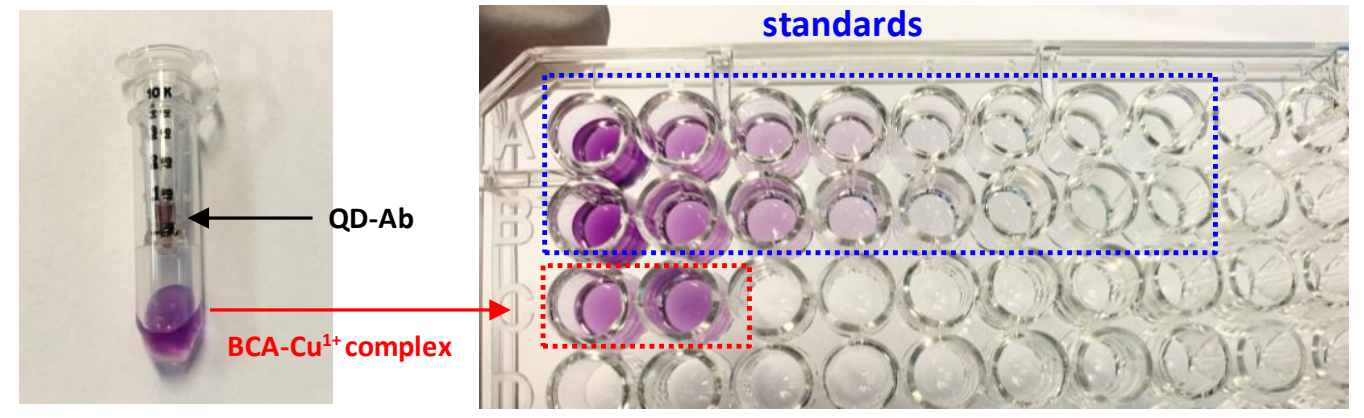

D

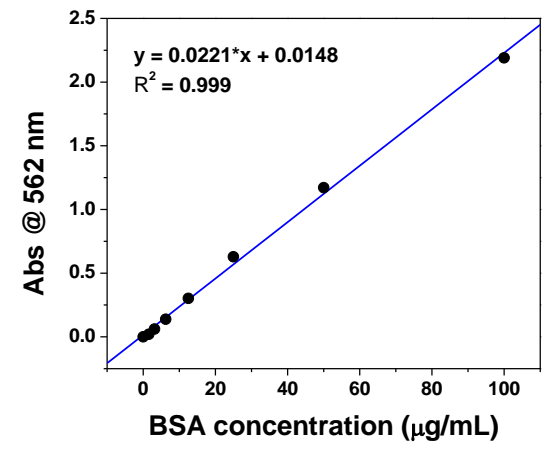

$\mathbf{E}$

\begin{tabular}{ll}
\multicolumn{2}{|c}{ BCA assay of QD-Ab } \\
\hline Average Abs. @ $562 \mathrm{~nm}$ & 1.206 \\
Extracted antibody concentration $(\mu \mathrm{g} / \mathrm{mL})$ & 53.9 \\
Antibody molar concentration $(\mu \mathrm{M})$ & 0.385 \\
QD molar concentration $(\mu \mathrm{M})$ & 0.343 \\
Average number of antibodies per QD & 1.12
\end{tabular}

Figure S4. (A) Agarose gel electrophoresis image of QD-BDNF conjugates (left) and the control LA/HisPIMA-ZW/N ${ }_{3}-$ QDs $\left(\mathrm{QD}-\mathrm{N}_{3}\right)$. (B) Zeta-potential values of QD-BDNF conjugates (-4.5 mv) and LA/HisPIMA-ZW/N ${ }_{3}-$ QDs (-11.4 mv) dispersed in PBS (0.1X, pH 7.4). The net negative potential correlates with the mobility shifts shown in panel A. The net negative potential of QD-N $\mathrm{N}_{3}$ is the combined contribution of the $\mathrm{COOH}$ and sulfobetaine groups in the coating. Overall, the smaller zeta potential for the QD-BDNF conjugates reflects the effects of conjugation with BDNF on the overall size and charge of the conjugates compared to QDs only. (C) White light image of the centrifugal filtration device (cutoff $=10 \mathrm{kDa}$, Millipore) used for the separating of bicinchoninic acid- $\mathrm{Cu}^{+1}$ complex from QD-Ab conjugates, after incubation of the conjugates with the BCA Working Reagent. Two replicates of each sample were analyzed using a 96-well plate. (D) Standard curve assembled from the BCA assay, with the raw data provided in the Table S1. (E) Summary of the absorption data used to extract the antibody concentration in the sample of QD-Ab conjugates, along with the deduced average valence of QD-conjugates. 


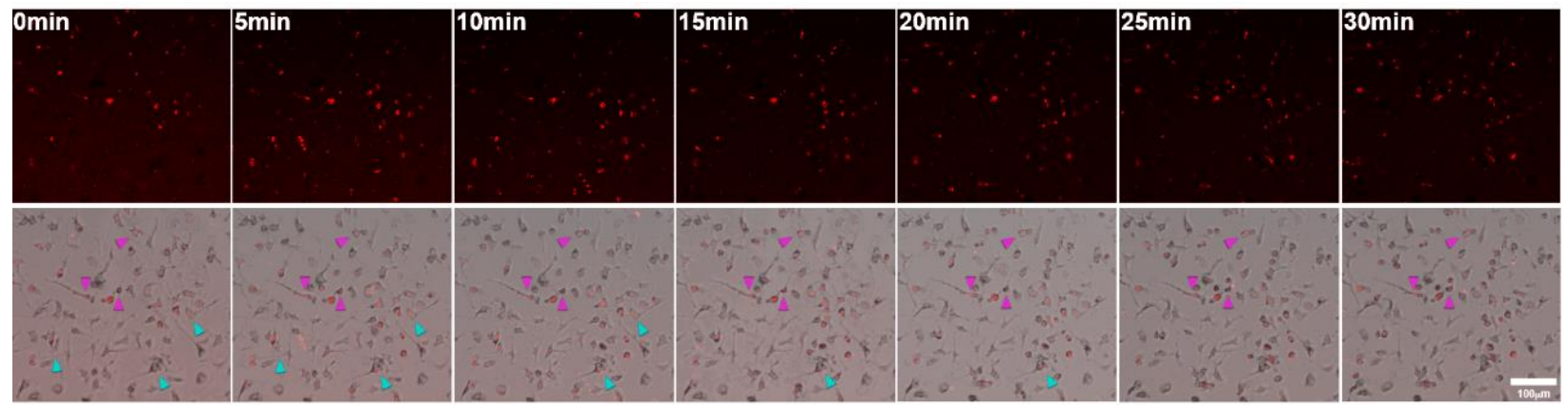

Figure S5. Time-lapse fluorescence images of BDNF-QD conjugates induced TrkB endocytosis and activation in live neuronal cells over time. The images were collected every 5 min interval up to $30 \mathrm{~min}$. The top panels show QD fluorescence images and the bottom panels show composite images of QD fluorescence and differential interference contrast (DIC).
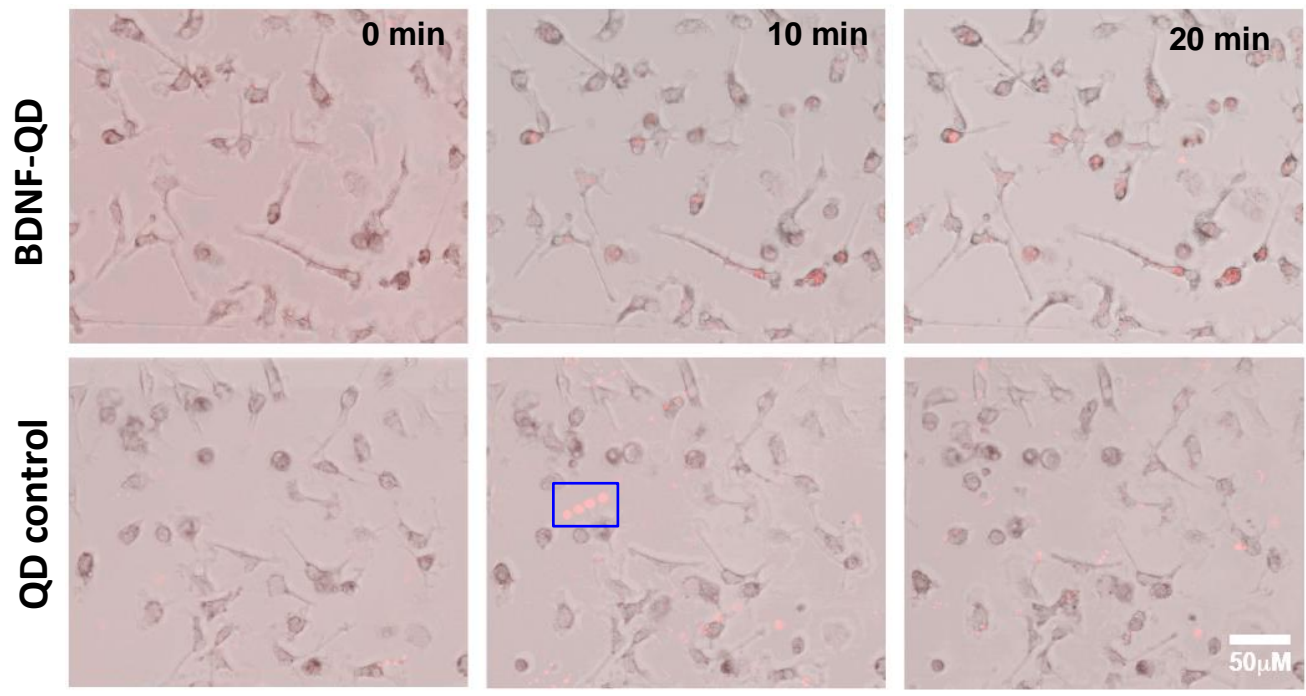

Figure S6. Time-lapse fluorescence images of neuronal cells incubated with BDNF-QD conjugates and QD control (no BDNF conjugation). Compared with BDNF-QD conjugates (upper panel), there was littleto-no uptake observed in the control experiment (lower panel). We should note that the red spots shown in the QD control panels (e.g., blue box) are artefacts of the instrumentation, not attributed to any QD signal. 

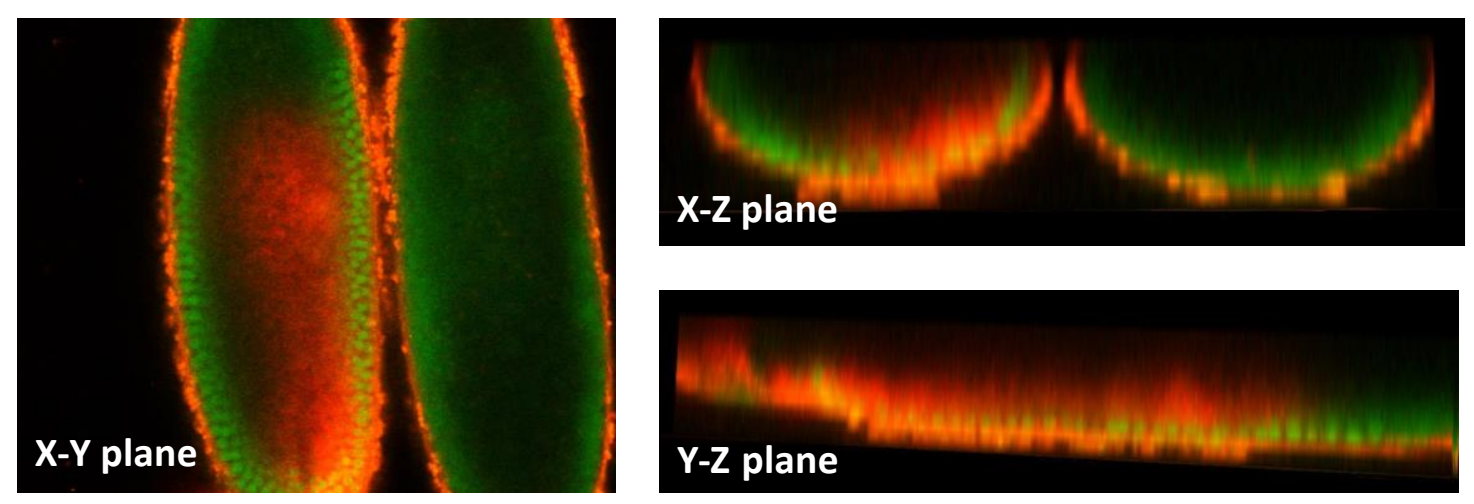

Figure S7. Overlaid fluorescence images (upper focal plane) of two Drosophila melanogaster embryos, recorded upon injection of QD solution into the left one only.

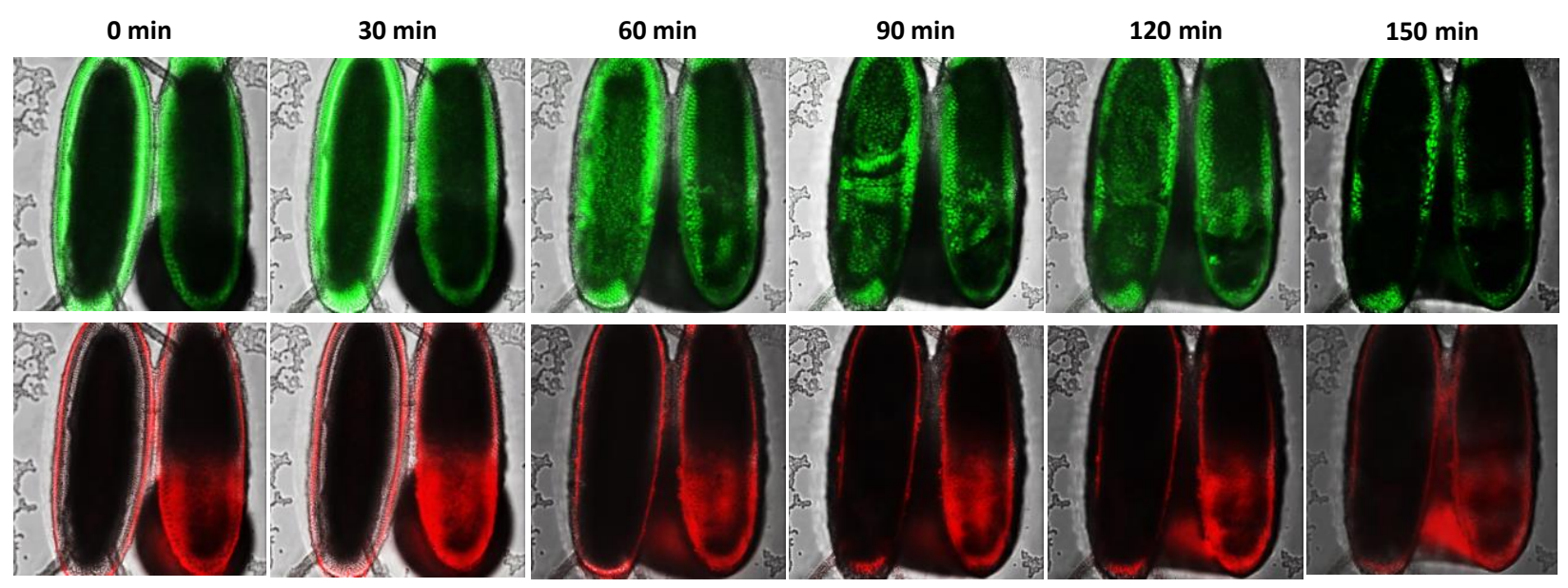

Figure S8. Overlaid fluorescence and transmittance images of two Drosophila melanogaster embryos, recorded after injection of QDs in the right one only. The images were captured every 30 min up to 150 $\min$. 


\section{References}

[1] Murray, C. B., Norris, D. J., and Bawendi, M. G. (1993) Synthesis and characterization of nearly monodisperse $\mathrm{CdE}$ ( $\mathrm{E}=\mathrm{S}$, Se, Te) semiconductor nanocrystallites., J. Am. Chem. Soc. 115, 8706-8715.

[2] Peng, Z. A., and Peng, X. G. (2001) Formation of high-quality CdTe, CdSe, and CdS nanocrystals using CdO as precursor, J. Am. Chem. Soc. 123, 183-184.

[3] Dabbousi, B. O., RodriguezViejo, J., Mikulec, F. V., Heine, J. R., Mattoussi, H., Ober, R., Jensen, K. F., and Bawendi, M. G. (1997) (CdSe)ZnS core-shell quantum dots: Synthesis and characterization of a size series of highly luminescent nanocrystallites, J. Phys. Chem. B 101, 9463-9475.

[4] Hines, M. A., and Guyot-Sionnest, P. (1996) Synthesis and characterization of strongly luminescing ZnS-Capped CdSe nanocrystals, J. Phys. Chem. 100, 468-471.

[5] Reiss, P., Bleuse, J., and Pron, A. (2002) Highly luminescent CdSe/ZnSe core/shell nanocrystals of low size dispersion, Nano Lett. 2, 781-784.

[6] Wang, W., Ji, X., Kapur, A., Zhang, C., and Mattoussi, H. (2015) A Multifunctional Polymer Combining the Imidazole and Zwitterion Motifs as a Biocompatible Compact Coating for Quantum Dots, J. Am. Chem. Soc. 137, 14158-14172.

[7] Susumu, K., Oh, E., Delehanty, J. B., Blanco-Canosa, J. B., Johnson, B. J., Jain, V., Hervey, W. J., Algar, W. R., Boeneman, K., Dawson, P. E., and Medintz, I. L. (2011) Multifunctional Compact Zwitterionic Ligands for Preparing Robust Biocompatible Semiconductor Quantum Dots and Gold Nanoparticles, J. Am. Chem. Soc. 133, 9480-9496.

[8] Kim, G., Yoo, C. E., Kim, M., Kang, H. J., Park, D., Lee, M., and Huh, N. (2012) Noble Polymeric Surface Conjugated with Zwitterionic Moieties and Antibodies for the Isolation of Exosomes from Human Serum, Bioconjugate Chem. 23, 2114-2120.

[9] Susumu, K., Mei, B. C., and Mattoussi, H. (2009) Multifunctional ligands based on dihydrolipoic acid and polyethylene glycol to promote biocompatibility of quantum dots, Nat. Protocols 4, 424-436.

[10] Wang, W., Kapur, A., Ji, X., Zeng, B., Mishra, D., and Mattoussi, H. (2016) Multifunctional and High Affinity Polymer Ligand that Provides Bio-Orthogonal Coating of Quantum Dots, Bioconjugate Chem. 27, 2024-2036. 